\title{
A TRADUÇÃO LITERÁRIA NO ENSINO DE LÍNGUAS
}

\author{
LA TRADUCCIÓN LITERARIA EN LA ENSEÑANZA DE LENGUAS
}

\section{LITERARY TRANSLATION IN LANGUAGE TEACHING}

\author{
Joselma Maria NOAL ${ }^{1}$ \\ Artur Emílio Alarcon VAZ ${ }^{2}$ \\ Daniele Corbetta PILLETI ${ }^{3}$
}

RESUMO: O presente artigo visa a compartilhar os resultados do projeto de pesquisa Juana Manuela Gorriti: análise e tradução. Desenvolvido com graduandos do curso de Letras Português/Espanhol, na Universidade Federal do Rio Grande - FURG, esse projeto tem o objetivo de melhorar tanto o conhecimento de língua espanhola, quanto o de língua portuguesa dos acadêmicos. Após a contextualização do projeto, sintetizamos o marco teórico e a metodologia adotados, para então dar exemplos da análise das traduções realizadas pelos alunos e, finalmente, procedemos às considerações finais.

PALAVRAS-CHAVE: Tradução literária. Ensino de línguas. Juana Manuela Gorriti

RESUMEN: El presente artículo pretende compartir los resultados del proyecto de investigación Juana Manuela Gorriti: análisis y traducción. Desarrollado con graduandos del curso de Letras Português/Espanhol, en la Universidade Federal do Rio Grande - FURG, ese proyecto tiene como objetivo mejorar tanto el conocimiento de lengua española, como el de lengua portuguesa de los académicos. Después de la contextualización del proyecto, sintetizamos el marco teórico y la metodología adoptados, para luego ejemplificar con el análisis de las traducciones realizadas por los alumnos y, finalmente, presentamos las consideraciones finales.

PALABRAS CLAVE: Traducción literaria. Enseñanza de lenguas. Juana Manuela Gorriti

ABSTRACT: This article aims at sharing the results/outcomes of the research project Juana Manuela Gorriti: análise e tradução. Developed with undergraduates, in the Portuguese/Spanish course, at Universidade Federal do Rio Grande - FURG, the

\footnotetext{
${ }^{1}$ Universidade Federal do Rio Grande - (FURG). Professora Assistente. Língua Espanhola. Mestre em Letras (PUCRS). Doutoranda em História da Literatura (FURG). E-mail: joselmanoal@ gmail.com.

${ }^{2}$ Universidade Federal do Rio Grande - (FURG). Professor associado, atua na área de Literatura. Doutor em Literatura Comparada pela UFMG. E-mail: arturvaz@ furg.br.

${ }^{3}$ Universidade Federal do Rio Grande - (FURG). Professora Adjunta no Instituto de Letras e Artes. Doutoranda em Ciências da Linguagem (área de concentração: Tradutologia) da Universidad Nacional de Córdoba (2016). E-mail: danielepiletti@furg.br.
} 
objective of this project is to improve both the knowedge about Spanish and Portuguese languages as well. After contextualizing the project, we synthesized the theoretical framework and the methodology used which was followed by examples of the translation anlyses accomplished by the students. Finally, we provided the final considerations.

KEYWORDS: Literary translation. Language teaching. Juana Manuela Gorriti

\section{Contextualização do projeto}

O ensino do espanhol como Língua Adicional (LA), na atualidade, não se restringe somente à abordagem comunicativa, devido a diferentes fatores históricos, sociais e culturais. O ponto de partida deve ser motivar o aluno, realizando atividades interdisciplinares que contemplem as sutis diferenças entre as línguas, neste caso português e espanhol, evidenciando os aspectos (inter)culturais (LEFFA; IRALA, 2014), que podem, por exemplo, ser trabalhados por meio da literatura na sala de aula de língua.

A crença de que a integração desses aspectos deveria ser tratada como relevante pelo professor de línguas levou-nos a realizar o referido projeto, dado que contribui para a aprendizagem autônoma e que, além de capacitar os envolvidos no domínio linguístico, também contribui para seu enriquecimento cultural, histórico, político e social. Leffa e Irala (2014, p. 275) afirmam que "os aspectos de ordem histórica, geográfica e política devem, com urgência, fazerem-se mais presentes na formação do futuro docente".

Os textos literários selecionados para a tradução foram escritos no século XIX e retratam o período político, histórico, social e cultural da Argentina daquele momento, que deve ser entendido pelo leitor brasileiro contemporâneo, tarefa de responsabilidade dos aprendizes, no papel de tradutores literários.

Esta proposta fundamenta-se também na necessidade de repensar o espaço atualmente dado no Brasil às obras produzidas pela argentina Juana Manuela Gorriti (1816-1892), praticamente desconhecida nos meios literários e acadêmicos brasileiros, já que não há traduções de obras completas para a língua portuguesa, mesmo após mais de um século de sua morte e décadas após seus textos terem entrado em domínio público. 
Esse intercâmbio entre os países latino-americanos é oportuno, devido à enorme diferença de status dessa autora no Brasil e em outros países. Embora as obras estejam inseridas entre os clássicos latino-americanos do século XIX e sejam reimpressas até hoje, como na inclusão da obra Dreams and realities (GORRITI, 2003) na Coleção "Biblioteca da América Latina", pela editora Oxford, seu nome no Brasil é raramente citado entre obras de mulheres que influenciaram na reflexão feminista da América Latina.

A pouca produção acadêmica no Brasil sobre a obra dessa escritora foi comprovada numa busca nos currículos do sistema Lattes e no Banco de Teses e Dissertações da CAPES, na qual foram encontrados poucos pesquisadores brasileiros da obra de Juana Manuela Gorriti. Outro indicador é a presença de um único romance dessa autora na Biblioteca Nacional Brasileira. Em comparação, na Biblioteca Nacional da Argentina, há oitenta e dois livros com textos de autoria de Gorriti. Igualmente, na Biblioteca Nacional do Chile, há onze romances e, na Biblioteca Nacional do Peru, quatorze obras. Dados como esses demonstram a viabilidade de que, com a tradução de sua obra ao português brasileiro, aumentem também a apresentação e a publicação de artigos, além de dissertações, teses e livros sobre a autora, principalmente através dos integrantes do grupo de pesquisa.

Portanto, uma das formas de aproximar a escritora do público leitor brasileiro é a análise, tradução e publicação de suas obras. Assim, formou-se uma equipe de alunos, coordenados por duas professoras de língua espanhola com experiência em tradução e um professor de literatura com experiência na análise e recuperação de textos do século XIX, todos vinculados ao Instituto de Letras e Artes.

\section{Referencial teórico}

Conforme Albir (2013, p. 63), além do domínio linguístico,

el traductor literario necesita de unas competencias específicas (una competencia literaria): amplios conocimientos literarios y culturales y determinadas aptitudes relacionadas con el funcionamiento de esos textos (buenas habilidades de escritura, creatividad, etc.), 
dado que tais competências permitirão a solução de problemas específicos de tradução, como questões de estilística (compreensão de metáforas e expressões idiomáticas), e também a intervenção da dimensão diacrônica e o estilo do autor nas relações socioculturais no contexto do Texto de Origem (TO).

Arrojo (1996) afirma que não existe nem tradução nem leitura que sejam neutras e que o tradutor é, em certo sentido, um coautor do texto que traduz, fato esse que estabelece uma interseção com as teorias da linguagem que se preocupam com o uso funcional da língua, pois o tradutor leva em consideração tanto o contexto sociocultural do autor, como o contexto do público alvo.

Lefevere (1985) afirma que toda tradução é uma reescrita e, como tal, implica numa manipulação, pois os tradutores-reescritores manipulam os originais, para fazer que se ajustem à ideologia e à poética da época do Texto Meta (TM). Sendo assim, adota-se, neste trabalho, o conceito de ideologia do referido autor, que a entende como o entrelaçado de forma, convenção e crenças que ordena as ações do tradutor. Segundo o autor, os componentes que formam a poética são dois: um inventário que abrange os recursos literários e outro que tem relação com influências ideológicas, este último denominado funcional. Isto esclarece que o tradutor deve levar em consideração o universo do leitor do TO e o do TM, pois ambos muitas vezes têm uma grande distância temporal e cultural. Isso pode ser exemplificado no projeto desenvolvido, posto que os tradutores tiveram que aproximar o texto escrito pela autora argentina do século XIX do leitor brasileiro do século XXI.

Lefevere (1997) entende que o universo do discurso pode ter repercussão na tradução por ser um conjunto de conhecimentos, crenças, conceitos e costumes que compõem uma cultura em uma determinada época. Além disso, a linguagem também intervêm na tradução por ser o modo como se usa e se manipula a língua para conseguir determinados efeitos.

Nesse mesmo sentido, Toury (1995) apresenta justificativas para a existência de regras, normas e idiossincrasias ao longo do processo tradutório. Entre elas, destaca os diversos tipos textuais ou tipos de público, o que leva o tradutor a adotar diferentes estratégias, daí a necessidade de que a prática tradutória seja pensada mediante normas estabelecidas em consonância com políticas socioculturais específicas e contextos históricos. Toury entende por norma a tradução de ideias e valores gerais 
compartilhados por uma comunidade em relação com o que está bem ou mal, adequado ou inadequado; além disso, uma norma deve ser aplicável a situações específicas. Dessa forma, trata-se de induções socioculturais específicas de uma cultura e de um período histórico.

A partir do conceito de norma, pode-se diferenciar a regularidade de comportamentos em situações recorrentes. O autor afirma que a norma pode ser aplicada não só em traduções de todo tipo, mas também em todas as etapas do ato tradutório e, consequentemente, em todos os níveis de geração de um produto de tradução. As premissas dos Estudos Descritivos da Tradução de Toury (1980) propõem o reconhecimento da literatura como um sistema cultural que inclui a situação histórica, cultural e social do texto e destaca seu impacto na atividade tradutória.

Cabe destacar ainda que a concepção adotada neste texto sobre a tradutologia, criada por Hurtado Albir (2013), é de que se trata de uma atividade cognitiva, ou seja, não é apenas a decodificação de uma língua a outra, mas também, e principalmente, um ato comunicativo e uma operação textual. Esta premissa justifica o papel didático da tradução no ensino de línguas apresentado neste artigo.

Rodríguez (1996, p. 110) mostra que "el traductor no nace; se hace" e cita que o aluno, ao realizar atividades de tradução em sala de aula, aperfeiçoará tanto a Língua Materna (LM) quanto a LA nos mais diversos aspectos linguísticos, ao afirmar que o estudante "pondrá a prueba su destreza mediante la traducción continuada de una variedad de material textual real". Afirma ainda, que as traduções realizadas poderão ser comparadas com as dos colegas e cada um poderá explicar suas escolhas em detrimento de outras opções de tradução. Baseados nessas reflexões, trabalhamos no projeto de pesquisa, para que, dessa forma, os integrantes do projeto possam aprimorar seus conhecimentos, por meio da discussão das diferentes versões preliminares até chegarem ao Texto Meta Final $\left(\mathrm{TM}_{2}\right)$, sob a orientação dos docentes.

\section{Metodologia}

No curso de Licenciatura em Letras Português/Espanhol da referida universidade, curso composto por oito semestres, são ofertadas disciplinas optativas de tradução, nas quais são realizadas oficinas com diversos materiais a fim de que os 
alunos percebam diferenças entre as traduções técnica e literária e, deste modo, sintamse mais preparados, instrumentalizados e aptos para o exercício da tradução literária.

A seleção dos acadêmicos que participaram do projeto - realizada entre os matriculados na disciplina "Tradução de textos em Língua Espanhola I" - foi feita pela análise de seu desempenho ao receberem os insumos, por intermédio da correção de traduções de pequenos textos literários (fragmentos dos próprios contos da autora) que eram avaliados pelos coordenadores do projeto. Foram selecionados graduandos do quinto semestre, levando em conta que o tradutor literário deve ter uma sensibilidade que ultrapasse o conhecimento linguístico, considerando a criatividade e a complexidade de seu trabalho. A partir desse semestre, espera-se que o graduando tenha o perfil do tradutor literário que se revela na "fidelidade" (TOURY, 2004 [1995]) ao estilo do autor e ao contexto sociocultural e na consciência de sua responsabilidade ao recriar a obra literária.

Quanto ao corpus de análise, os contos selecionados para a tradução foram escolhidos pelos coordenadores, seguindo os critérios de grau de complexidade estilística da autora, período de publicação e temática abordada. Os alunos, de forma individual, leram os livros de contos Sueños y realidades (1907 [1865]) e Panoramas de la vida (1876), que pertencem à primeira fase de escrita da autora, sendo selecionados os seguintes contos: El ángel caído; Una apuesta; La novia del muerto; Caer de las nubes; La hija del mashorquero; El guante negro; Si practicas el mal, no esperes el bien; El emparedado; El lucero del manantial; Yerbas y alfileres; Una noche de agonía e Un drama en 15 minutos. A análise individual dos contos detalhou inicialmente elementos textuais (enredo, personagens, tempo e espaço), bem como o contexto sociohistórico, analisando também diversos interesses: feminismo, historiografia, sociologia, política, geografia, entre outros, com a finalidade de aproximar o aprendiz do universo do Texto de Origem (TO).

Após a leitura e a análise dos contos, os acadêmicos procederam - ainda individualmente - à tradução de apenas um conto cada um e, para isso, tiveram livre acesso a todo tipo de dicionários; podiam traduzir em suas casas ou em um espaço reservado a eles dentro da universidade (uma sala com computadores e acesso à internet) e estabeleceu-se um prazo de um mês para que entregassem a tradução. A partir da aplicação do questionário inicial, as variantes de sexo, idade e nível 
socioeconômico foram neutralizadas, dado que as tradutoras são todas mulheres, com idades entre 22 e 25 anos e têm o mesmo nível socioeconômico (C - Classe média).

Ao finalizarem a tradução, obteve-se o Texto Meta Preliminar $\left(\mathrm{TM}_{1}\right)$, e, logo após, os coordenadores revisaram - inicialmente em reuniões coletivas quinzenais cada conto, apontando as dificuldades a serem solucionadas e, finalmente, foi elaborado o Texto Meta Final $\left(\mathrm{TM}_{2}\right)$, com atendimento e orientação individual. O estágio atual do projeto consiste na revisão final dos $\mathrm{TM}_{2}$, sob a responsabilidade dos três coordenadores, verificando as dificuldades encontradas pelos alunos, tais como o contexto histórico do ambiente dos contos, as metáforas e outras figuras de linguagem, as expressões idiomáticas, o léxico do espanhol do século XIX, o uso de heterossemânticos, as referências mitológicas, etc, que serão trabalhados de forma mais aprofundada, posteriormente, em sala de aula, para aperfeiçoar ambos os idiomas. Porém, ao identificar as próprias dificuldades, os alunos já demonstram aumentar a sua competência linguística no par de idiomas estudado, conforme preconizado por Pegenaute (1996).

Com relação ao contexto histórico do século XIX, dados e personagens históricos como Juan Manuel de Rosas, Juan Lavalle, Juan Martín de Pueyrredón, Carlos María de Alvear receberam notas explicativas nas traduções, a fim de aproximar o texto original da Argentina do século XIX do leitor brasileiro do século XXI. Na tradução final, optou-se por manter os nomes próprios dos personagens históricos e dos locais públicos, o que exigiu dos acadêmicos a pesquisa sobre a real existência dos personagens e dos locais mencionados nos contos. Desse modo, os estudantes, tradutores literários em formação, tiveram a oportunidade de aprimorar-se não só em questões gramaticais, mas também conhecer aspectos históricos, políticos, geográficos e sociais da Argentina do século XIX.

Além do esperado perfil do tradutor literário, outros critérios estabelecidos pelos coordenadores do projeto foram observados na atividade tradutória, para que os alunos aumentem sua competência linguística na LM e na LA. São eles:

1. Domínio da LM e da LA, já que a tradução requer um grande conhecimento da língua adicional que será aperfeiçoada; foram seguidos autores como Leffa (1988) e Hurtado Albir (1999), que afirmam que se deve usar este tipo de atividade em níveis intermediários e avançados de ensino; 
2. Uma língua materna comum a todo o grupo; no caso do nosso projeto, trata-se de brasileiras que aprendem espanhol em contexto formal de ensino superior no Brasil, fora do contexto de imersão na LA;

3. Um grupo adulto, pois a tradução como ferramenta didática exige certa capacidade de reflexão e certa maturidade intelectual, podendo-se afirmar que este exercício apresenta um alto nível de raciocínio;

4. O objetivo do curso, pois a competência comunicativa é a finalidade do curso de ensino de LA; o que não impede que um licenciado em Letras possa atuar como tradutor, dado que no curso de Letras dessa universidade há oferta de disciplinas optativas na área de tradução.

\section{Exemplos da análise inicial}

A seguir, são apresentados alguns fragmentos extraídos dos contos que compõem o projeto, dada a extensão limite deste texto. Para efeitos de organização, os fragmentos foram elencados por tipo de dificuldades e neles aparecem diferentes tipos de questões gramaticais, lexicais e estilísticas. Para este artigo, foram selecionadas questões recorrentes nos diferentes $\mathrm{TM}_{1}$, que foram percebidos e corrigidos pelos aprendizes, gerando os $\mathrm{TM}_{2}$.

\section{Sintagma nominal}

Nos exemplos a seguir, é possível observar, nos TO, que o adjunto adnominal aparece anteposto ao núcleo, dentro do sintagma nominal, o que, embora permitido, é diferente do estabelecido pela ordem canônica dos dois idiomas ${ }^{4}$, indicando que a autora optou por inverter a ordem tradicional. Em casos como esses, é possível ver que os aprendizes, nos $\mathrm{TM}_{1}$, mantêm a ordem canônica e, ao perceberem que a inversão devese a uma opção da autora, reelaboram os $\mathrm{TM}_{2}$, para seguirem uma das diretrizes apontadas por Toury (2004) no sentido de manter fidelidade ao TO e revelar ao leitor do $\mathrm{TM}_{2}$ a estilística do texto traduzido.

${ }^{4}$ Conforme a Moderna Gramática Portuguesa (2009) e a Nueva Gramática de la Lengua Española (2010), no que diz respeito ao português e ao espanhol, respectivamente. Cabe destacar que ambas são gramáticas normativas, pois, nas traduções sob análise, buscou-se o uso da norma padrão, tal como preconizado por Toury (2004). 
$\mathrm{TO}^{5}$ [En aquel heterogéneo círculo doblemente alumbrado por el gás y las brasas del hogar.]

$\mathrm{TM}_{1}$ [Naquele círculo heterogêneo duplamente alumbrado pelo gás e pelas brasas do lar.]

$\mathrm{TM}_{2}$ [Naquele heterogêneo círculo duplamente alumbrado pelo gás e pelas brasas do lar.]

$\mathrm{TO}^{6}$ [Silencio solo interrumpido por el prolongado y lamentable canto del coyиyu.]

$\mathrm{TM}_{1}$ [Silêncio só interrompido pelo canto prolongado e lamentável do coyuyu.]

$\mathrm{TM}_{2}$ [Silêncio só interrompido pelo prolongado e lamentável canto do coyuyu.]

$\mathrm{TO}^{7} \quad$ [Al lado de aquel sangriento lecho se hallaba de rodillas una mujer de estatura elevada.]

$\mathrm{TM}_{1}$ [Ao lado daquele leito sangrento encontrava-se de joelhos uma mulher de estatura elevada.]

$\mathrm{TM}_{2}$ [Ao lado daquele sangrento leito encontrava-se de joelhos uma mulher de estatura elevada.]

$\mathrm{TO}^{8} \quad$ [Los habitantes de los vecinos campos se encontraban todavía en las noches del estío.]

$\mathrm{TM}_{1}$ [Os habitantes dos campos vizinhos encontravam-se ainda nas noites de verão.]

$\mathrm{TM}_{2}$ [Os habitantes dos vizinhos campos encontravam-se ainda nas noites de verão.]

$\mathrm{TO}^{9} \quad$ [Pero la voz alegre de su padre disipó su penosa emoción.]

$\mathrm{TM}_{1} \quad$ [Mas a voz alegre de seu pai dissipou sua emoção penosa.]

$\mathrm{TM}_{2}$ [Mas a voz alegre de seu pai dissipou sua penosa emoção.]

\section{Vocativo}

Outro traço detectado foi o uso do vocativo, no qual a autora argentina mantém a ordem canônica do idioma espanhol, fato que provavelmente deve-se ao uso pragmático do vocativo nesse idioma. Ao ver os vocativos nos TO, mantendo a ordem do adjunto adnominal posposto ao núcleo, dentro do sintagma nominal, os aprendizes fizeram o mesmo. Porém, ao entenderem que a autora fez isso para manter a ordem canônica no TO, verificaram como era o uso do vocativo na sua LM e perceberam que pragmaticamente era ao contrário: adjunto adnominal anteposto ao núcleo, dentro do

5 "El emparedado"

6 "El lucero del manantial"

7 "El guante negro"

8 "La novia del muerto"

9 "Un drama en 15 minutos" 
sintagma nominal (BECHARA, 2009). Dessa forma, decidiram manter a ordem canônica do vocativo na LM nos fragmentos do $\mathrm{TM}_{2}$, para um melhor entendimento do público leitor do texto traduzido, como feito nos TO. Essas ações refletem o amadurecimento dos aprendizes tanto na LM como na LA, por meio da atividade tradutória como ferramenta de ensino e aprendizagem.

$\mathrm{TO}^{10}$ [¿Qué pesar oscurece su frente, amada mía?]

$\mathrm{TM}_{1} \quad$ [Que pesar escurece seu semblante, amada minha?]

$\mathrm{TM}_{2}$ [Que pesar escurece seu semblante, minha amada?]

$\mathrm{TO}^{11}$ [Dios mío, murmuró Vital, ten piedad de mi amor.]

$\mathrm{TM}_{1} \quad$ [Deus meu, murmurou Vital, tenha piedade de meu amor.]

$\mathrm{TM}_{2}$ [Meu Deus, murmurou Vital, tenha piedade de meu amor.]

$\mathrm{TO}^{12}$ [Esta misma adhesión, madre mía, realza más la magnidad de ese corazón generoso.]

$\mathrm{TM}_{1}$ [Esta mesma adesão, mãe minha, realça mais a magnitude desse coração generoso.]

$\mathrm{TM}_{2}$ [Esta mesma adesão, minha mãe, realça mais a magnitude desse coração generoso.]

$\mathrm{TO}^{13}$ [Un cuchillo, hija mía, un cuchillo es más expeditivo.]

$\mathrm{TM}_{1}$ [Uma faca, filha minha, uma faca é mais eficiente.]

$\mathrm{TM}_{2}$ [Uma faca, minha filha, uma faca é mais eficiente.]

\section{Tempo verbal}

Outro aspecto relevante que demonstra o progresso na aprendizagem do aluno dá-se na percepção de que há uma diferença na correlação de tempos verbais, em função de não haver correspondência direta entre todos os tempos de ambos os idiomas. Os exemplos selecionados permitem verificar que, em um primeiro momento, os aprendizes não percebem que devem realizar essa correlação, recorrendo ao uso de locuções verbais no $\mathrm{TM}_{1}$ para traduzir, por exemplo, o pretérito perfeito composto do espanhol. Ao perceberem que tanto o pretérito perfeito composto, quanto o pretérito

10 "El guante negro"

11 "La novia del muerto"

12 "El lucero del manantial"

13 "Una noche de agonía" 
perfeito simples traduzem-se ao português como pretérito perfeito, refizeram o $\mathrm{TM}_{2}$ corretamente.

$\mathrm{TO}^{14}$ [Nada ha cambiado en torno mío.]

$\mathrm{TM}_{1} \quad$ [Nada tem mudado ao meu redor.]

$\mathrm{TM}_{2}$ [Nada mudou ao meu redor.]

$\mathrm{TO}^{15}$ [El sol ha sido brillante. $]$

$\mathrm{TM}_{1} \quad$ [O sol tem sido brilhante.]

$\mathrm{TM}_{2} \quad$ [O sol foi brilhante.]

$\mathrm{TO}^{16}$ [Las flores me han enviado sus más suaves perfumes.]

$\mathrm{TM}_{1} \quad$ [As flores têm me enviado seus mais suaves perfumes.]

$\mathrm{TM}_{2}$ [As flores enviaram-me seus mais suaves perfumes.]

$\mathrm{TO}^{17}$ [Las melodías que han callado.]

$\mathrm{TM}_{1} \quad$ [As melodias que têm calado.]

$\mathrm{TM}_{2}$ [As melodias que calaram.]

\section{Regência verbal}

Outro aspecto gramatical com o qual foi possível aferir um aprimoramento linguístico nos graduandos foi o uso adequado da regência verbal. Como menciona Duarte (1998), a semelhança entre elementos gramaticais nas línguas espanhola e portuguesa destaca-se como um dos pontos de maior dificuldade. Nesse caso, o estudo da regência verbal diferente nos dois idiomas permitiu que o uso inadequado da preposição não se fossilizasse (GARGALLO, 1993), como é possível observar nos exemplos a seguir:

$\mathrm{TO}^{18} \quad$ Los malos pensamientos, hijos de los celos, que convierten al ángel en demônio.]

$\mathrm{TM}_{1}$ [Os maus pensamentos, filhos do ciúmes, que convertem ao anjo em demônio.]

$\mathrm{TM}_{2}$ [Os maus pensamentos, filhos do ciúmes, que convertem o anjo em demônio.]

14 "El guante negro" 15 "El guante negro" 16 "El guante negro" 17 "El guante negro" 18 "El guante negro" 
TO ${ }^{19}$ [Todo esto con la decisión instantânea y rápida que distingue a los grandes capitanes.]

$\mathrm{TM}_{1}$ [Tudo isto com a decisão instantânea e rápida que distingue aos grandes capitães.]

$\mathrm{TM}_{2}$ [Tudo isto com a decisão instantânea e rápida que distingue os grandes capitães.]

$\mathrm{TO}^{20}$ [¡Y estrechó en un solo abrazo a los dos amantes!]

$\mathrm{TM}_{1}$ [E apertou em um só abraço aos dois amantes!]

$\mathrm{TM}_{2} \quad$ [E apertou em um só abraço os dois amantes!]

$\mathrm{TO}^{21}$ [Su presencia intimidaba a las chicas y las impedía entregarse a los compases de Strauss.]

$\mathrm{TM}_{1}$ [Sua presença intimidava às meninas e as impedia entregar-se aos compassos de Strauss.]

$\mathrm{TM}_{2}$ [Sua presença intimidava as meninas e as impedia de entregar-se aos compassos de Strauss.]

$\mathrm{TO}^{22}$ [Y con la mirada y el oído atento, interrogaba angustiosamente a la noche y al silencio.]

$\mathrm{TM}_{1}$ [E com o olhar e o ouvido atento, interrogava angustiosamente à noite e ao silêncio.]

$\mathrm{TM}_{2}$ [E com o olhar e o ouvido atento, interrogava angustiosamente a noite e o silêncio.]

\section{Colocação pronominal}

Outra dificuldade gramatical que demonstrou ter sido superada com a atividade tradutória foi o uso da colocação pronominal em ambos os idiomas. Como em espanhol os verbos conjugados recebem os pronomes na posição de próclise - conforme a Nueva Gramática de la Lengua Española (2010) -, nos $\mathrm{TM}_{1}$ os pronomes aparecem nessa mesma posição. Ao estudar o uso da colocação pronominal em português e verificar que esse uso proclítico acontece na linguagem coloquial - conforme Silva (2000) - e perceber que na linguagem escrita formal usa-se a ênclise - conforme Bechara (2009) -, excetuando os casos em que os pronomes são atraídos por outra partícula e devem

19 "La novia del muerto"

20 "Un drama en 15 minutos"

21 "El emparedado"

22 "La hija del mashorquero" 
assumir a posição de próclise, os $\mathrm{TM}_{2}$ foram modificados, demonstrando esse aprendizado.

$\mathrm{TO}^{23}$ [Su voz se extinguió en un suspiro.]

$\mathrm{TM}_{1} \quad$ [Sua voz se extinguiu em um suspiro.]

$\mathrm{TM}_{2} \quad$ [Sua voz extinguiu-se em um suspiro.]

$\mathrm{TO}^{24}$ [Y se le condene al relato de una coincidencia.]

$\mathrm{TM}_{1}$ [E o condene ao relato de uma coincidência.]

$\mathrm{TM}_{2}$ [E condene-o ao relato de uma coincidência.]

$\mathrm{TO}^{25}$ [El portero que velaba en la primera antesala se inclinó profundamente.]

$\mathrm{TM}_{1} \quad$ [O porteiro que velava na primeira antessala se inclinou profundamente.]

$\mathrm{TM}_{2} \quad$ [O porteiro que velava na primeira antessala inclinou-se profundamente.]

$\mathrm{TO}^{26}$ [Se encuentra en el capítulo octavo de las Confesiones de San Agustín.]

$\mathrm{TM}_{1} \quad$ [Se encontra no capítulo oitavo das Confissões de Santo Agostinho.]

$\mathrm{TM}_{2}$ [Encontra-se no capítulo oitavo das Confissões de Santo Agostinho.]

\section{Léxico}

Além das questões gramaticais, o léxico também oferece grandes obstáculos para realizar uma tradução. Geralmente, quando os alunos não sabem o significado de uma palavra, buscam-no no dicionário. O problema reside no fato de olharem, em geral, apenas a primeira acepção da palavra, comprovado na leitura dos $\mathrm{TM}_{1}$, sem perceber que quase sempre há mais de uma acepção e que a escolha entre elas depende do contexto. A seguir, mostram-se exemplos nos quais é possível perceber que os alunos refletiram sobre o uso do léxico mais apropriado para determinado contexto.

$\mathrm{TO}^{27}$ [No he pensado aún en curar tu herida.]

$\mathrm{TM}_{1}$ [Não pensei ainda em curar tua ferida.]

$\mathrm{TM}_{2}$ [Não pensei ainda em tratar tua ferida.]

$\mathrm{TO}^{28}$ [Imprimió en ella un beso.]

23 "Yerbas y alfileres"

24 "El emparedado"

25 "El guante negro"

26 "El emparedado"

27 "El guante negro"

28 "El guante negro" 
$\mathrm{TM}_{1} \quad$ [Imprimiu nela um beijo.]

$\mathrm{TM}_{2}$ [Deu-lhe um beijo.]

$\mathrm{TO}^{29}$ [El rostro bronceado y grave de Bracho.]

$\mathrm{TM}_{1} \quad$ [O rosto bronzeado e grave de Bracho.]

$\mathrm{TM}_{2} \quad$ [O rosto bronzeado e sério de Bracho.]

$\mathrm{TO}^{30}$ [Un terrible recuerdo brilló como un relámpago en la memoria de Wenceslau, que llevó vivamente las manos al pecho.]

$\mathrm{TM}_{1}$ [Uma terrível lembrança brilhou como um relâmpago na memória de Wenceslau, que levou vivamente as mãos ao peito.]

$\mathrm{TM}_{2}$ [Uma terrível lembrança brilhou como um relâmpago na memória de Wenceslau, que levou rapidamente as mãos ao peito.]

No primeiro exemplo abaixo, é possível perceber que a palavra "grave" foi traduzida por "grave", no entanto, ao analisar o contexto da oração na qual aparece essa palavra, seria mais apropriado traduzir por "sério", dado que tal vocábulo é polissêmico e, no exemplo, está sendo usado no seu "significado figurado" (NEWMARK, 2010 [1992]). Já no exemplo posterior, é possível perceber que o aprendiz realizou uma tradução adequada já na primeira versão, já que o contexto demonstra a relação com o som, pois se refere ao som do eco, ou seja, a palavra está usada no "significado físico" (NEWMARK, 2010 [1992]).

$\mathrm{TO}^{31}$ [El otro niño respondió con acento grave y resignado.]

$\mathrm{TM}_{1} \quad$ [O outro menino respondeu com sotaque grave e resignado.]

$\mathrm{TM}_{2} \quad$ [O outro menino respondeu com tom sério e resignado.]

$\mathrm{TO}^{32}$ [La hechicera sevillana entró ... despertando los graves ecos.]

$\mathrm{TM}_{1}=\mathrm{TM}_{2} \quad$ [A feiticeira sevilhana entrou ... despertando os graves ecos.]

\section{Expressões idiomáticas}

Ao analisar os $\mathrm{TM}_{1}$ e $\mathrm{TM}_{2}$, no que diz respeito às expressões idiomáticas "lexia complexa indecomponível, conotativa e cristalizada em um idioma pela tradição cultural" (XATARA, 2001, p. 51) - que aparecem nos TO, é possível verificar que os

29 "El guante negro"

30 "El guante negro"

31 "La hija del mashorquero"

32 "Una apuesta" 
aprendizes tiveram dificuldades em compreender as expressões idiomáticas na LA, ao buscar o significado literal, o sentido denotativo. Porém, num segundo momento, ao entender o sentido conotativo, mostraram-se capazes de elaborar o significado da sequência de palavras em seu contexto e não do vocábulo isolado, percebendo, assim, o sentido conotativo, traduzindo com êxito a expressão para a LM, como se pode observar nos exemplos a seguir:

$\mathrm{TO}^{33}$ [La verdad toda entera se mostro a sus ojos.]

$\mathrm{TM}_{1} \quad$ [A verdade completa mostrou-se a seus olhos.]

$\mathrm{TM}_{2} \quad$ [A verdade nua e crua mostrou-se a seus olhos.]

$\mathrm{TO}^{34}$ [El tiempo estaba representado en su más lata acción.]

$\mathrm{TM}_{1} \quad$ [O tempo estava representado em seu mais pesado dia.]

$\mathrm{TM}_{2} \quad$ [O tempo estava representado em seu dia mais cinzento.]

$\mathrm{TO}^{35}$ [Como prenda de amistad, respondió ella, alzando con graciosa coquetería la extremidad de su velo.]

$\mathrm{TM}_{1} \quad$ [Como prenda de amizade, respondeu ela, levantando com graciosa sedução a extremidade do seu véu.]

$\mathrm{TM}_{2}$ [Como prova de amizade, respondeu ela, levantando com graciosa sedução a extremidade do seu véu.]

$\mathrm{TO}^{36} \quad$ [Y es fama que nunca quiso casarse por no tener que sonreír... siquiera el día de la boda.]

$\mathrm{TM}_{1} \quad$ [E é fama que nunca quis casar-se por não ter que sorrir... sequer no dia do casamento.]

$\mathrm{TM}_{2}$ [E sabe-se que nunca quis casar-se por não ter que sorrir... sequer no dia do casamento.]

\section{Considerações finais}

Atividades como as descritas neste artigo permitiram que os acadêmicos ampliassem seus horizontes culturais, aperfeiçoando não somente a Língua Adicional, mas também ampliassem seu contato com questões culturais referentes à Argentina e a outros países citados nos contos, que permitem ao tradutor fazer, por exemplo, inferências sobre situações presentes no texto original, para poder traduzi-los de modo

33 "La hija del mashorquero"

34 "El emparedado"

35 "El guante negro"

36 "Una apuesta" 
adequado. Na formação do tradutor literário competente, o amadurecimento linguístico é um dos fatores mais significativos. Dessa forma, os acadêmicos, por meio da tradução literária, terão qualificado sua competência na LM e na LA, enriquecendo seu arcabouço teórico, metodológico e cognitivo, com vistas a preparar-se melhor para o mercado de trabalho em tradução.

O projeto de pesquisa encontra-se em fase final, na etapa de revisão linguística, com vistas à publicação da primeira antologia de contos de Juana Manuela Gorriti em língua portuguesa, inteiramente traduzida pelos alunos que participam do projeto. A qualificação dos graduandos está sendo comprovada a partir da revisão dos $\mathrm{TM}_{2}$, que demonstrou que a utilização da atividade tradutória em sala de aula, como recurso didático no ensino de línguas, contribui para o aperfeiçoamento tanto da LM quanto da LA, fato este que permite aos alunos ampliar os horizontes no mercado de trabalho, dado que terão um diferencial, por terem participado deste projeto e, com isso, adquirido novos conhecimentos sobre a prática tradutória, além de aspectos linguisticos e culturais.

Os resultados obtidos reafirmam que a implementação da atividade de tradução literária é eficaz para o crescimento profissional, pessoal e cultural dos agentes envolvidos no processo, pois instrumentaliza os acadêmicos de Letras para trabalharem língua e literatura de forma articulada, através da tradução.

\section{REFERÊNCIAS}

ARROJO, Rosemary. Os estudos da tradução na pós-modernidade, o reconhecimento da diferença e a perda da inocência. Cadernos de Tradução, Florianopólis, UFSC, v. 1, p. 64, 1996.

BECHARA, Evanildo. Moderna gramática portuguesa. São Paulo: Nova Fronteira, 2009 [1961].

CERVO, Irène Zohra Séréro. Tradução e ensino de línguas. 2003. 220f. Dissertação (Mestrado em Linguística Aplicada) - Instituto de Letras, Universidade de Brasília, Brasília, 2003.

DUARTE, Cristina Aparecida. Reflexiones sobre la enseñanza de las preposiciones españolas brasileños. In: IX Congreso Internacional de la ASELE - Español como Lengua Extranjera: Enfoque Comunicativo y Gramática. Santiago de Compostela, 1998. 
GARGALLO, Isabel Santos. Análisis contrastivo, análisis de errores e interlengua, en el marco de la Linguiística Contrastiva. Madrid: Síntesis, 1993.

GORRITI, Juana Manuela. Dreams and realities. New York: Oxford University, 2003. Trad. Sérgio Waisman.

GORRITI, Juana Manuela. Sueños y realidades. 2 v. Buenos Aires: La Nación, 1907.

GORRITI, Juana Manuela. Panoramas de la vida: colección de novelas, fantasías, leyendas y descripciones americanas. Buenos Aires: Imprenta y Librarías de Mayo, 1876.

HERNÁNDEZ, María Rosario. La traducción pedagógica en la clase de E/LE. In: Actas del VII Congreso ASELE, p. 249-255, 1998.

HURTADO ALBIR, Amparo. Traducción y Traductología. Introdução a Tradutología. 6 ed. Madrid: Cátedra, 2013.

HURTADO ALBIR, Amparo. Enseñar a traducir. Metodología na formação de tradutores e intérpretes. Madrid: Edelsa, 1999.

LEFEVERE, André. Traducción, reescritura y la manipulación del canon literario. Salamanca: Ediciones Colegio de España, 1997.

LEFEVERE, André. Why waste our time on rewrites? The trouble of interpretation and the role of rewriting in an alternative paradigm. In: HERMANS, Theo. The manipulation of literature: Studies in literary translation. London: Croom Helm, 1985. p. $215-243$.

LEFFA, Vilson João. Metodologia do ensino de línguas. In BOHN, H. I.;

VANDRESEN, P. Tópicos em linguística aplicada: o ensino de línguas estrangeiras. Florianópolis: Ed. da UFSC, 1988.

LEFFA, Vilson João; IRALA, Valesca Brasil. (Org.). Uma espiadinha na sala de aula. Pelotas: Educat, 2014.

REAL ACADEMIA ESPAÑOLA; ASOCIACIÓN DE ACADEMIAS DE LA LENGUA ESPAÑOLA. Nueva Gramática de la Lengua Española. Manual. 1 ed. Buenos Aires: Espasa, 2010.

PEGENAUTE RODRÍGUEZ, Luis. La traducción como herramienta didáctica. Contextos, Madrid, n. 27-28, p. 107-126, 1996.

SILVA, Michelle Aide Martignoni. A variação da colocação pronominal do português culto do Brasil. 2000. 237 f. Dissertação (Mestrado em Letras). Instituto de Letras. Universidade Federal Fluminense, Niterói, 2000. 
TOURY, Gideon. In search of a Theory of Translation. Tel Aviv: Tel Aviv University, 1980.

TOURY, Gideon. Descriptive translation studies and beyond. Amsterdam: John Benjamins, 1995.

TOURY, Gideon. Los estudios descriptivos de traducción y más allá. Metodología da investigação em estudos de tradução. Madrid: Cátedra, 2004.

XATARA, Cláudia Maria. O ensino do léxico: as expressões idiomáticas. Trabalhos em linguística aplicada, v. 37, p. 49-59, 2001.

\section{Como referenciar este artigo}

NOAL, Joselma Maria.; VAZ, Artur Emílio Alarcon.; PILLETIA, Daniele Corbetta. Tradução literária no ensino de línguas. Rev. EntreLínguas, Araraquara, v. 3, n. 2, p. 318-335, jul./dez. 2017. Disponível em:

<https://doi.org/10.29051/rel.v3.n2.2017.9410>. E-ISSN: 2447-3529.

Submetido em: 06/02/2017

Revisões requeridas: 11/10/2017

Aprovado em: 02/11/2017 